\title{
Genç Antepfıstığı Ağaçlarında Farklı Sulama Yöntemlerinin Gelişim Parametrelerine Etkisi
}

\author{
Cuma DEMiR ${ }^{1}$, Atılgan ATILGAN ${ }^{2 *}$ \\ ${ }^{1}$ Süleyman Demirel Üniversitesi, Ziraat Fakültesi, Tarımsal Yapılar ve Sulama Anabilim Dalı, Isparta \\ ${ }^{2}$ Süleyman Demirel Üniversitesi, Ziraat Fakültesi, Tarımsal Yapılar ve Sulama Bölümü, Isparta \\ *Sorumlu yazar: atilganatilgan@sdu.edu.tr
}

Öz

Çalışmada farklı sulama yöntemleri kullanılarak bitkinin gelişim parametreleri incelenmiştir. Denemede kullanılan yabani antepfıstığı (Pistaciavera L.) fidesine on günde bir sulama yapılmıştır. Sulama uygulamaları Haziran ile Eylül ayları arasında yürütülmüştür. Farklı sulama sistemleri kullanılan konular SP (sulanmayan parsel), DS (damla sulama), KS (karık sulama), YS (yağmurlama sulama) olarak bölümlendirilmiştir. Bu konularda sulama sonrası genç antepfıstığı fidesinin gelişim parametreleri (yaprak sayısı, yaprak alan indeksi, dal sayısı, gövde genişliği ve bitki boy uzunluğu) ölçümleri yapıımıştır. Deneme konularından olan DS'nin toplam sulama suyu miktarı $471.05 \mathrm{~mm}$ olarak, YS'nin toplam sulama suyu miktarı $591.63 \mathrm{~mm}$ olarak, KS'nin ise toplam sulama suyu miktarı $942.10 \mathrm{~mm}$ olarak hesaplanmıştır. Deneme konularında \%5 istatistik varyans analizine sonucuna göre en yüksek bitki gelişim parametre değerleri DS konusunda yaprak sayısı 24 adet, gövde yüksekliği $83 \mathrm{~cm}$, dal sayısı 3adet, gövde genişliği 19 $\mathrm{mm}$ ve yaprak alan indeksi 4.2 olarak elde edilirken en düşük değerler YS konusunda yaprak sayısı 13 adet, gövde yüksekliği $56 \mathrm{~cm}$, dal sayısı 2 adet, gövde genişliği $13 \mathrm{~mm}$ ve yaprak alan indeksi 2.3 olarak elde edilmiştir.

Anahtar Kelimeler: Antepfıstığı, Farklı Sulama Yöntemi, Gelişim Parametreleri, Nizip

\section{Effects of Different Irrigation Methods on Development Parameters in Youth Pistachio Trees}

\begin{abstract}
In the study, plant growth parameters were studied using different irrigation systems. The wild pistachios (Pistaciavera L.) seedlings which used in the experiment were irrigated at every ten days. Irrigation practices were carried out between June and September. Different irrigation systems such as $\mathrm{NI}$ (non-irrigated plots), DI (drip irrigation), FI (furrow irrigation) and SI (sprinkler irrigation) were determined. After irrigation, measurements of the growth parameters (number of leaves, leaf area index, number of branches, plant height and width of the body), of young pistachio seedling were determined. The total amount of irrigation water in drip irrigation as $471.05 \mathrm{~mm}$, the total amount of irrigation water in sprinkler as $591.63 \mathrm{~mm}$ and the total amount of irrigation water in furrow irrigation as $942.10 \mathrm{~mm}$ was calculated. According to the results of the trial subject to the $5 \%$ statistical analysis of variance highest plant growth parameter values are determined in drip irrigation. The number of leaf sheets 24 , body height $83 \mathrm{~cm}$, the number of branches $3,19 \mathrm{~mm}$ body width and leaf area index as 4.2 was calculated. The lowest value of sprinkler irrigation on the number of leaf sheets 13, body height 56 $\mathrm{cm}$, the number of branches $2,13 \mathrm{~mm}$ body width and leaf area index of 2.3 was obtained.
\end{abstract}

Keywords: Pistachio, Different Irrigation Methods, Growth Parameters, Nizip 


\section{Giriş}

Antepfıstığı türlerinden olan Pistaciavera L, botanik olarak Anacardiaceae familyasından olup, meyve ağacı ve süs bitkisi olarak varlığının olduğu belirtilmektedir (Özbek, 1978; Hendricks ve Ferguson, 1995; Kaşka, 1998; Carusa, 2001). Antepfıstığının iki gen merkezi vardır. (1) Orta Asya Gen Merkezi (Hindistan'ın Kuzeyi, Afganistan, Tacikistan, Pakistan) (2) Yakın Doğu Gen Merkezi (Anadolu, Kafkasya, İran ve Türkmenistan) (Ulusaraç, 1993).Dünya'da Antepfıstığı üretiminde İran ilk sırada, ikinci sırada ise Amerika Birleşik Devletleri gelmektedir. Ülkemiz ise her yıl sürekli üretim yapılmadığı halde bu ülkelerin ardından üçüncü sırada yer almaktadır (Anonim, 2014). Antepfıstığı üretiminin yoğun olarak yapıldığı Türkiye'de en son olarak 56 il'de yetiştiriciliğin gerçekleştiği belirtilmektedir. Buna rağmen yetiştiriciliğin en önemli merkezi \%94'lik bir dilime sahip Güneydoğu Anadolu Bölgesidir (Tekin ve ark, 1990).

Antepfıstığı ağaçları, kuraklığa dayanıklı olduğundan çok az miktarda su ile yaşamını devam ettirebilir. Ancak, kuraklığa dayanıklı olması, optimum bitki gelişimi için az bir suyun yeterli olduğu anlamına gelmediği belirtilmektedir (Goldhamer, 1995). Ülkemizde sulama konusunda ilk çalışma, 1973 yılında Antepfıstığı Araştırma Enstitüsünde yapılmış (Bilgen, 1973 ve 1982; Kuru, 1992), bu yapılan çalışmalardan sonra sulama ile ilgili araştırmalar önem kazanarak hızlı bir artış göstermiştir (Kanber ve ark., 2000).

Antepfıstığının (Siirt çeşidi) su tüketimi ve sulama programının belirlenmesi için yapılan bir çalışmada; antepfıstığı fidesinin 45 gün aralıklarla 3 kez sulanması gerektiği, sulamanın Haziran ayı başından Eylül ayı başına kadar uygulanması gerektiği belirtilmektedir. Çalışmada, antepfıstığının mevsimlik sulama suyu gereksinimini 450 $\mathrm{mm}$, su tüketiminin ise $600 \mathrm{~mm}$ olduğunu belirtmişlerdir (Bilgel ve ark., 1999). Hendricks ve Ferguson, (1995) antepfıstığı yetiştiriciliğinde sulamanın, özellikle sulama suyu miktarı, zamanı ve uygulama yönteminin önemli olduğunu belirtmektedirler.

$\mathrm{Bu}$ çalışmanın amacı, antepfıstığı yetiştiriciliğinde farklı sulama yöntemlerinin genç antepfıstığı fidelerinde, gelişim parametrelerinde değişiklerinin belirlenmesi hedeflenmiştir. Bu amaçla uygulama alanı 4 parsele ayrılmış ve bir parselde kontrol amaçlı sulama yapılmamıştır. Diğer parsellerde ise sırasıyla karık sulama, damla sulama ve yağmurlama sulama yöntemleri uygulanmıştır.

\section{Materyal ve Metot}

Araştırma, antepfıstığı yetiştiriciliğinin yoğun olduğu Güneydoğu Anadolu Bölgesi, Gaziantep İli, Nizip İlçesinde gerçekleşmiştir. Deneme alanı Nizip'in Günaltı köyünde 800 $\mathrm{m}^{2}$ bir alanda yürütülmüştür. Deneme alanının rakımı 400 metre olup, $37^{\circ} 7^{\prime}$ doğu enlemi, $37^{\circ}$ 917' kuzey boylamındadır. Deneme alanına ait toprak özellikleri Çizelge 1'de verilmiştir (Demir, 2016)

Denemede, farklı sulama yöntemleri (damla sulama (DS), karık sulama (KS), mini spring sulama (YS), sulanmayan parsel (SP)) kullanılarak antepfıstığında gelişim parametreleri ele alınmış ve 4 farklı parsel hazırlanmıştır (Şekil 1). Her bir deneme konuları alanı $200 \mathrm{~m}^{2}$ dir $(8 \mathrm{~m} \times 25 \mathrm{~m})$. Sulama konuları arasındaki etkileşimi engellemek için deneme parselleri arasına 5'er m boşluk bırakılmıştır (Demir, 2016). 
Çizelge 1. Deneme alanına ait toprağın bazı özellikleri

Figure 1. Some soil properties of the experimental area

\begin{tabular}{|c|c|c|c|c|cc|}
\hline $\begin{array}{c}\text { Toprak Derinliği } \\
(\mathrm{cm})\end{array}$ & $\begin{array}{c}\text { Hacim } \\
\text { ağırlığı (gr } \\
\left.\mathrm{cm}^{-3}\right)\end{array}$ & $\begin{array}{c}\text { Bünye } \\
\text { Sınıfı }\end{array}$ & $\begin{array}{c}\text { Tarla } \\
\text { Kapasitesi }\end{array}$ & $\begin{array}{c}\text { Solma } \\
\text { Noktası }\end{array}$ & \multicolumn{2}{|c|}{ Kullanılabilir Su Tutma } \\
(\%) & $\mathrm{mm}$ \\
\hline $0-30$ & 1.33 & Kil & 37.71 & 21.13 & 16.58 & 66.2 \\
\hline $30-60$ & 1.15 & Kil & 37.69 & 21.08 & 16.61 & 57.3 \\
\hline
\end{tabular}

\begin{tabular}{|l|l|l|l|l|l|l|l|l|l|l|l|l|}
\hline & SP1 & & & & & & & & & \\
\hline
\end{tabular}

Şekil 1. Parsellerdeki sulama yöntemlerinin diziliş durumu

Figure 1. The pattern of irrigationn methods in the parcels 
Damla sulama parsellerine her bitki sırasına 2 adet lateral döşenmiş, damlatıcı aralıkları $80 \mathrm{~cm}$ ve debisi $4 \mathrm{~L} \mathrm{~h}^{-1}$ olan basınç düzenleyicili on-line damlatıcılar yerleştirilmiştir. Debisi $70 \mathrm{~L} \mathrm{~h}^{-1}$, ıslatma çapı 4 $\mathrm{m}$ olan mini yağmurlama başlıkları ise her ağaç altına yerleştirilmiştir. Karık sulama parsellerinde ise karıklara $600 \mathrm{~L} \mathrm{~h}^{-1}$ debi ile sulama suyu uygulanmıştır (Demir, 2016). Deneme parsellerine uygulanan sulama suyu miktarı deneme alanına kurulmuş olan buharlaşma kabından ölçülen 10 günlük yığışımlı buharlaşma miktarı göz önüne alınarak aşağıdaki eşitlik yardımıyla hesaplanmıştır (Güngör ve ark., 2004). Sulama aralığı ise 10 gündür.

$$
I=E_{p} x k_{p} x P
$$

Eşitlikte; I, uygulanan sulama suyu miktarı (mm), $E_{p}$, kapta ölçülen yığışımlı buharlaşma miktarı (mm), kp, kap katsayısı (1 olarak alınmıştır), P, ıslatılan alan yüzdesi (damla sulamada $\% 50$, mini spring sulama $\% 62.8$, karık sulama \%100 olarak alınmıştır). 1 nolu eşitlikte hesaplanan sulama suyu miktarları deneme alanındaki parsel büyüklüğü dikkate alınarak hacim $\left(\mathrm{m}^{3}\right)$ olarak hesaplanmıs ve her bir parsele verilecek su miktarları su sayaçları ile kontrol edilerek verilmiştir.

Damla Sulama: Eşitlikte; P, ıslatılan alan yüzdesi $(\%), S_{d}$, damlatıcı aralığı $(m)$ ve $S_{s}$, ağaç sıra aralığı $(\mathrm{m})$ (damlatıcı aralığı $\left(S_{d}\right) 1 \mathrm{~m}$ olarak alınmıştır) (Güngör ve ark., 2004).

$$
\mathrm{P}=100 \frac{2 S d}{S s}
$$

Mikro Yağmurlama Sulama: Ortalama yağmurlama hızı aşağıdaki eşitlik yardımıyla hesaplanmıştır.

$$
\mathrm{I}_{\mathrm{y}}=\frac{4 q}{\pi D 2}
$$

Eşitlikte; Iy, yağmurlama hızı $\left(\mathrm{mm} \mathrm{h}^{-1}\right)$, başlık debisi, $\left(I h^{-1}\right)$ ve $D$, başlık ıslatma çapı (m).

Meyve bahçelerinde her ağacın altına bir küçük yağmurlama başlığı yerleştirildiği zaman eşitlik 4 yardımıyla hesaplamalar yapılmaktadır.

$$
P=100 \pi D^{2} / 4 S_{a} S_{s}
$$

Eşitlikte; P, ıslatılan alan yüzdesi (\%), D, ıslatma çapı $(m), S_{a}$, sıra üzerinde ağaç aralığı $(m), S_{s}$, ağaç sıra aralığı $(m)$ (Güngör ve ark., 2004).

Deneme fidelerindeki bitki gelişim konuları her 10 günde bir ölçülmüştür. Gelişim parametrelerinde fide yüksekliği, fide gövde genişliği ve dal sayısı bütün dikili fidelerde ölçümü yapılmıştır. Fakat yaprak alan indeksi ve yaprak sayısı tesadüfi olarak seçilen sıralardan alınan yaprak örnekleriyle ölçümler yapılmıştır (Demir, 2016). Çalışmada üzerinde durulan özellikler bakımından elde edilen veriler parametrik testlerin ön şartlarına bakılarak (normallik ve varyans homojenliği testleri) ve ön şartları sağladığı için tek yönlü varyans analizi tekniği ve tukey testi kullanılmıştır (Mendes, 2012).

\section{Araştırma Bulguları ve Tartışma}

Çalışma 2015 yılının Nisan ile Eylül ayları arasında, sulama uygulamaları ise Haziran ile Eylül ayları arasında yürütülmüştür. Bu amaçla gelişim parametreleri kapsamında boy uzunluğu, gövde kalınlığı, yaprak sayısı ve yaprak alan indeksi ölçümleri yapılmıştır. Sulama konularında uygulanacak toplam sulama suyu miktarları sırasıyla DS için $471.05 \mathrm{~mm}$, YS için $591.63 \mathrm{~mm}$ ve KS sulaması için $942.1 \mathrm{~mm}$ olarak hesaplanmıştır. Çalışmada farklı sulama yöntemlerinin antepfıstığı fidesindeki gövde yüksekliği değerleri ölçülmüş ve Şekil 2'de 
verilmiştir. Bu değerlere bakıldığında farklı sulama yöntemlerine göre gövde yüksekliği değerlerinin değiştiği görülmektedir. Gövde yükseklikleri SP konusunda $58 \mathrm{~cm}$, DS konusunda $83 \mathrm{~cm}$, KS ve YS konularında ise sırasıyla $51 \mathrm{~cm}$ ile $56 \mathrm{~cm}$ arasında değiştiği belirlenmiştir. Gövde yüksekliği özelliği bakımından elde edilen verilere yapılan varyans analizi sonucunda grupların ortalamaları arasındaki farklar istatistiksel olarak önemli $(p<0.01)$ bulunmuştur. Tukey testi sonuçları Çizelge 2'de ortalamalar üzerinde latin harfleri ile gösterilmiştir. Damla sulama uygulamasının gövde yüksekliği ortalaması $83 \mathrm{~cm}$ olarak bulunmuş ve diğer üç sulama yönteminden istatiksel olarak bir yüksekliğe sahiptir $(P<0.05)$. Diğer üç uygulama arasında istatiksel olarak (SP, KS, YS) önemli bir fark bulunmamıştır.

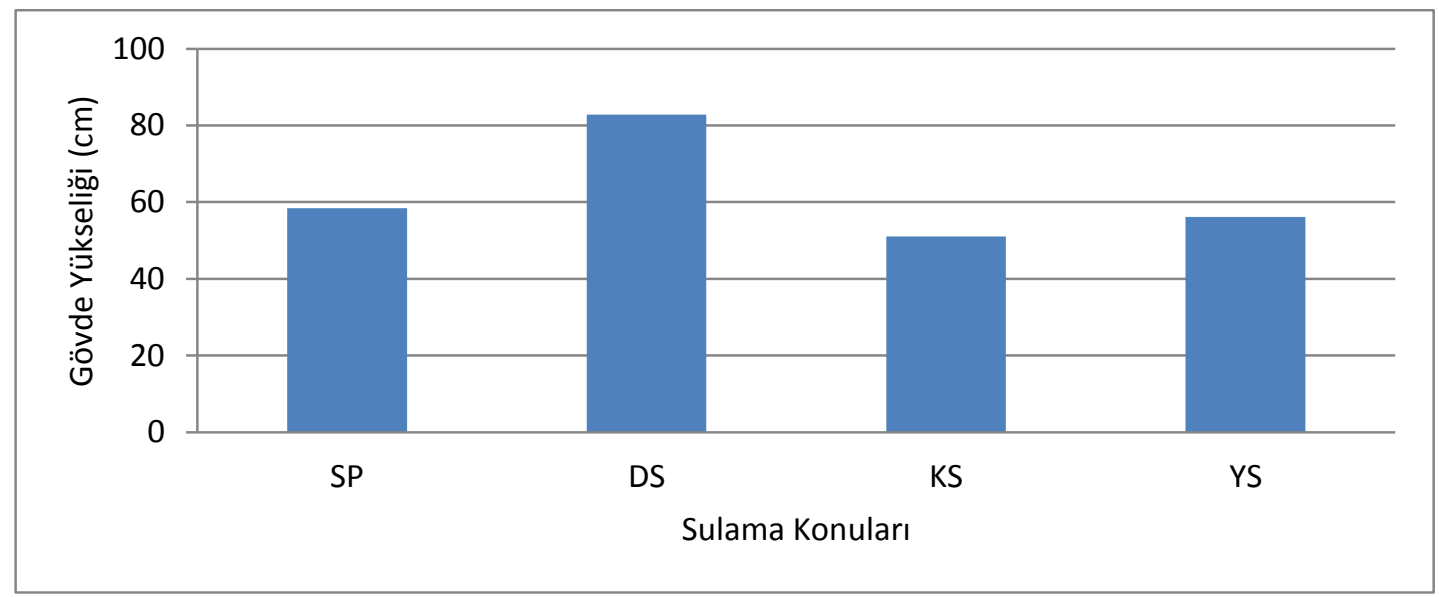

Şekil 2. Sulama konularında gövde yükseklikleri

Figure2. Body height in irrigation subjects

Çizelge 2. Gövde yüksekliği tanıtıcı özellik ve varyans analizi

Table2. The identifier feature and variance analysis of the body height

\begin{tabular}{|c|c|c|c|c|c|c|c|c|c|c|}
\hline $\begin{array}{c}\text { Değişken } \\
\text { Variable }\end{array}$ & $\begin{array}{c}\text { Grup } \\
\text { Group }\end{array}$ & $\mathrm{N}$ & $\mathrm{N}$ & $\begin{array}{c}\text { Ortalama } \\
\text { Mean }\end{array}$ & $\begin{array}{c}\text { StHata } \\
\text { SEMean }\end{array}$ & $\begin{array}{c}\text { StSapma } \\
\text { StDev }\end{array}$ & $\begin{array}{c}\text { VarKatsayısI } \\
\text { CoefVar }\end{array}$ & $\begin{array}{c}\text { Minimum } \\
\text { Minimum }\end{array}$ & $\begin{array}{c}\text { Medyan } \\
\text { Median }\end{array}$ & $\begin{array}{c}\text { Maksimum } \\
\text { Maxsimum }\end{array}$ \\
\hline Gövde yüksekliği & DS & 3 & 0 & $82.83 \mathrm{a}$ & 4.19 & 7.26 & 8.76 & 76.33 & 81.5 & 90.67 \\
\hline & KS & 3 & 0 & $51.067 \mathrm{~b}$ & 0.982 & 1.701 & 3.33 & 49.4 & 51 & 52.8 \\
\hline & SP & 3 & 0 & $58.37 \mathrm{~b}$ & 4.93 & 8.55 & 14.64 & 49.67 & 58.68 & 66.75 \\
\hline & YS & 3 & 0 & $56.17 \mathrm{~b}$ & 6.71 & 11.62 & 20.69 & 43.5 & 58.67 & 66.33 \\
\hline
\end{tabular}

Yine farklı sulama yöntemlerine göre dal sayısı değerlerinin değiştiği Şekil 3 'de görülmektedir. Dal sayısı SP konularında 2.9 adet, DS konusunda 2.8 adet, KS konusunda 2.7 adet, YS konusunda ise 2.6 adet olduğu belirlenmiştir. 


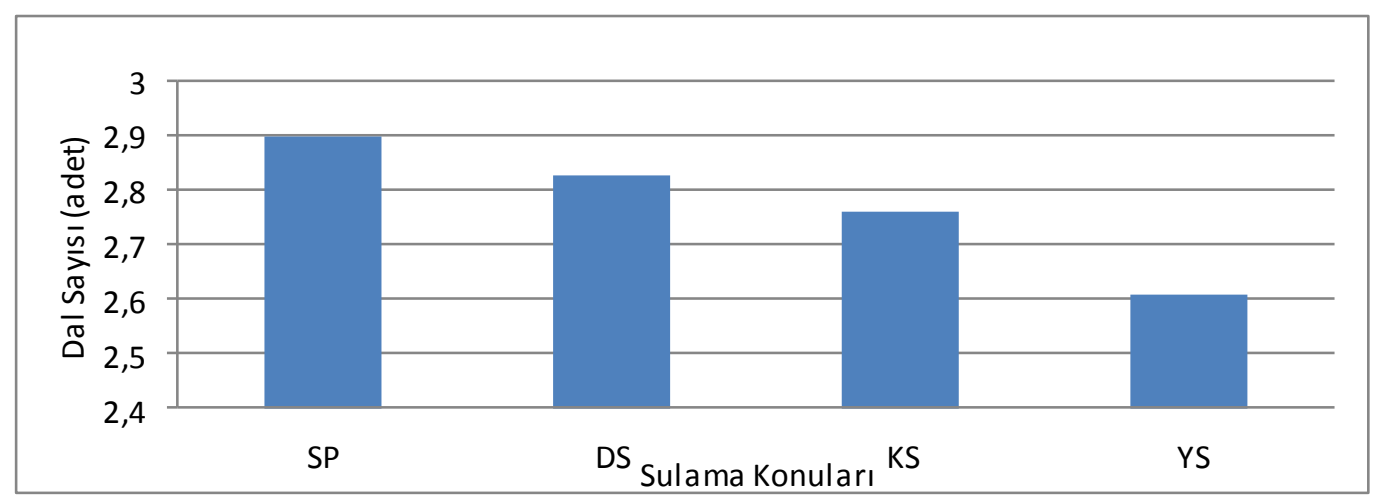

Şekil 3. Sulama konularında dal sayıları

Figure3. Number of branches in irrigation subjects

Çizelge 3. Dal sayısı tanıtıcı özellik ve varyans analizi

Table3.The identifier feature and variance analysis of the branch numbers

\begin{tabular}{|c|c|c|c|c|c|c|c|c|c|c|}
\hline $\begin{array}{c}\text { Değişken } \\
\text { Variable }\end{array}$ & $\begin{array}{c}\text { Grup } \\
\text { Group }\end{array}$ & $\mathrm{N}$ & $\mathrm{N} *$ & $\begin{array}{c}\text { Ortalama } \\
\text { Mean }\end{array}$ & $\begin{array}{c}\text { StHata } \\
\text { SEMean }\end{array}$ & $\begin{array}{c}\text { StSapma } \\
\text { StDev }\end{array}$ & $\begin{array}{c}\text { VarKatsayıSI } \\
\text { CoefVar }\end{array}$ & $\begin{array}{c}\text { Minimum } \\
\text { Minimum }\end{array}$ & $\begin{array}{c}\text { Medyan } \\
\text { Median }\end{array}$ & $\begin{array}{c}\text { Maksimum } \\
\text { Maxsimum }\end{array}$ \\
\hline Dal sayıSI & DS & 3 & 0 & 2.8 & 0.167 & 0.289 & 10.19 & 2.5 & 3 & 3 \\
\hline & KS & 3 & 0 & 2.7 & 0.145 & 0.252 & 9.1 & 2.5 & 2.8 & 3 \\
\hline & SP & 3 & 0 & 2.9 & 0.0506 & 0.0876 & 3.02 & 2.833 & 2.87 & 3 \\
\hline & YS & 3 & 0 & 2.6 & 0.309 & 0.536 & 20.52 & 2.0 & 2.833 & 3 \\
\hline
\end{tabular}

Dal sayısı özelliği bakımından yapılan varyans analizi sonucunda sulama uygulamalarının dala sayısı ortalamaları bakımından aralarındaki farklar istatiksel olarak önemli değildir. Çalışmada farklı sulama yöntemlerinin antepfıstığı fidesindeki gövde genişliği değerleri Şekil 4'te verilmiştir.
Şekil 4'e bakıldığında farklı sulama yöntemlerine göre gövde genişliği değerlerinin değiştiği görülmektedir. Gövde genişliği ortalamaları SP konusunda $15 \mathrm{~mm}$, DS konusunda $19 \mathrm{~mm}$, KS konusunda $13 \mathrm{~mm}$ ve YS konusunda ise $13 \mathrm{~mm}$ olarak belirlenmiştir.

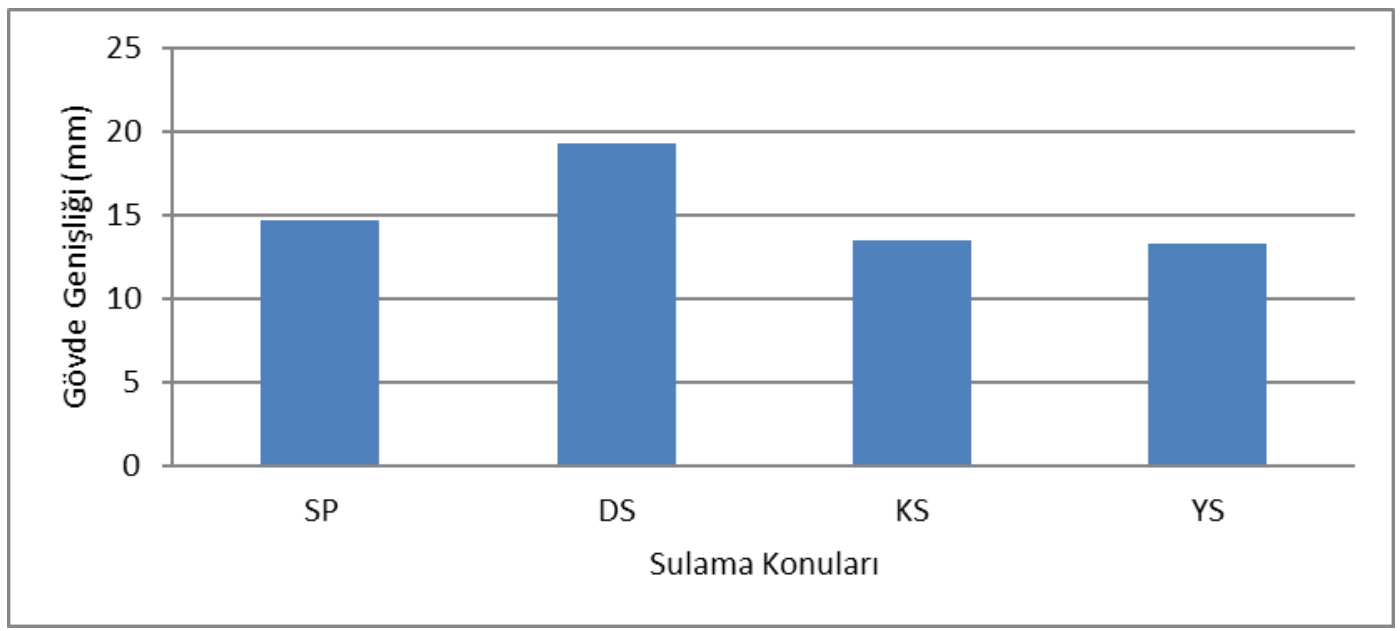

Şekil 4. Sulama konularında gövde genişlikleri

Figure4. Body width in irrigation subjects 
Çizelge 4. Gövde genişliği tanıtıcı özellik ve varyans analizi

Table 4. The identifier feature and variance analysis of the body width

\begin{tabular}{|c|c|c|c|c|c|c|c|c|c|c|}
\hline $\begin{array}{c}\text { Değişken } \\
\text { Variable }\end{array}$ & $\begin{array}{c}\text { Grup } \\
\text { Group }\end{array}$ & $\mathrm{N}$ & $\mathrm{N} *$ & $\begin{array}{c}\text { Ortalama } \\
\text { Mean }\end{array}$ & $\begin{array}{c}\text { StHata } \\
\text { SEMean }\end{array}$ & $\begin{array}{c}\text { StSapma } \\
\text { StDev }\end{array}$ & $\begin{array}{c}\text { VarKatsayısI } \\
\text { CoefVar }\end{array}$ & $\begin{array}{c}\text { Minimum } \\
\text { Minimum }\end{array}$ & $\begin{array}{c}\text { Medyan } \\
\text { Median }\end{array}$ & $\begin{array}{c}\text { Maksimum } \\
\text { Maxsimum }\end{array}$ \\
\hline Gövde genişliği & DS & 3 & 0 & 19 & 0.842 & 1.458 & 7.54 & 17.7 & 19.85 & 20.48 \\
\hline & KS & 3 & 0 & 13 & 0.648 & 1.122 & 8.33 & 12.55 & 13.147 & 14.722 \\
\hline & SP & 3 & 0 & 15 & 0.504 & 0.873 & 5.93 & 13.7 & 15.182 & 15.24 \\
\hline & YS & 3 & 0 & 13 & 1.14 & 1.97 & 14.86 & 11.2 & 13.53 & 15.12 \\
\hline
\end{tabular}

Gövde genişliği özelliği varyans analizi sonuçlarına göre sulama yöntemlerinin gövde genişliği bakımından aralarındaki farklar istatiksel olarak önemlidir $(p<0.01)$. Çizelge 3 incelendiğinde SP, KS ve YS sulama yöntemlerinin ortalamaları arasındaki farklar istatiksel olarak önemli değilken, Damla sulama yöntemi bu üç sulama yönteminden de istatiksel olarak önemli bir farka sahiptir $(\mathrm{P}<0.05)$.Şekil 5'e bakıldığında farklı sulama yöntemlerine göre yaprak sayısı değerlerinin değiştiği görülmektedir. Yaprak sayısı SP konusunda 16 adet, DS konusunda 24 adet, KS konusunda 15 adet ve YS konusunda ise 13 adet olduğu belirlenmiştir.

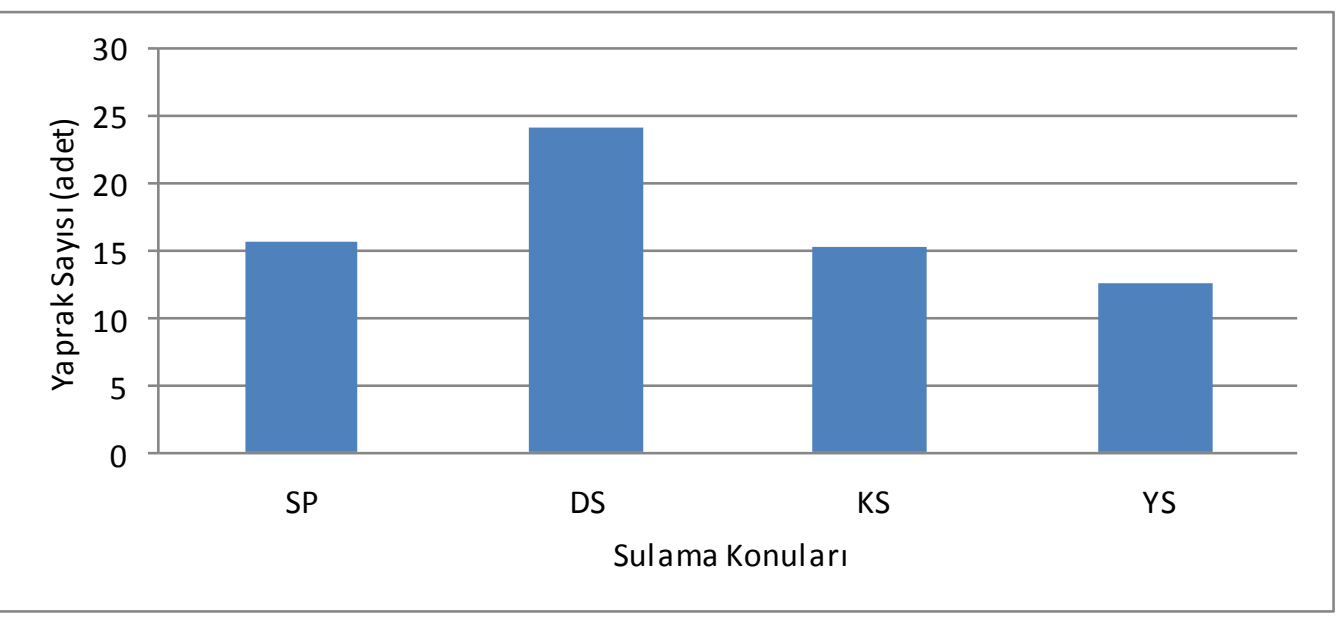

Şekil 5. Sulama konularında yaprak sayıları

Figure5. Leaf numbers in irrigation subjects

Çizelge 5. Yaprak sayısı tanıtıcı özellik ve varyans analizi

Table 5.The identifier feature and variance analysis of the leaf numbers

\begin{tabular}{|c|c|c|c|c|c|c|c|c|c|c|}
\hline $\begin{array}{c}\text { Değişken } \\
\text { Variable }\end{array}$ & $\begin{array}{c}\text { Grup } \\
\text { Group }\end{array}$ & $\mathrm{N}$ & $\mathrm{N}^{*}$ & $\begin{array}{c}\text { Ortalama } \\
\text { Mean }\end{array}$ & $\begin{array}{c}\text { StHata } \\
\text { SEMean }\end{array}$ & $\begin{array}{c}\text { StSapma } \\
\text { StDev }\end{array}$ & $\begin{array}{c}\text { VarKatsayısı } \\
\text { CoefVar }\end{array}$ & $\begin{array}{c}\text { Minimum } \\
\text { Minimum }\end{array}$ & $\begin{array}{c}\text { Medyan } \\
\text { Median }\end{array}$ & $\begin{array}{c}\text { Maksimum } \\
\text { Maxsimum }\end{array}$ \\
\hline Yaprak sayISI & DS & 3 & 0 & 24 & 1.13 & 1.95 & 8.06 & 22 & 25 & 25.67 \\
\hline & KS & 3 & 0 & 15 & 2.8 & 2.8 & 18.36 & 12 & 16.67 & 17 \\
\hline & SP & 3 & 0 & 16 & 1.014 & 1.014 & 6.43 & 14.667 & 15.96 & 16.667 \\
\hline & YS & 3 & 0 & 13 & 1.171 & 1.171 & 9.32 & 11.333 & 12.667 & 13.667 \\
\hline
\end{tabular}


Yaprak sayısı özelliği bakımından yapılan varyans analizi sulama yöntemlerinin aralarındaki farklar istatiksel olarak önemlidir $(p<0.01)$. Çizelge 4 incelendiğinde SP, KS ve YS sulama yöntemlerinin ortalamaları arasındaki farklar istatiksel olarak önemli değilken, Damla sulama bu üç sulama yönteminden de istatiksel olarak önemli bir farka sahiptir $(\mathrm{P}<0.05)$. Çalışmada farklı sulama yöntemlerinin antepfıstığı fidesindeki yaprak alan indeksi değerleri ise Şekil 6'da verilmiştir.

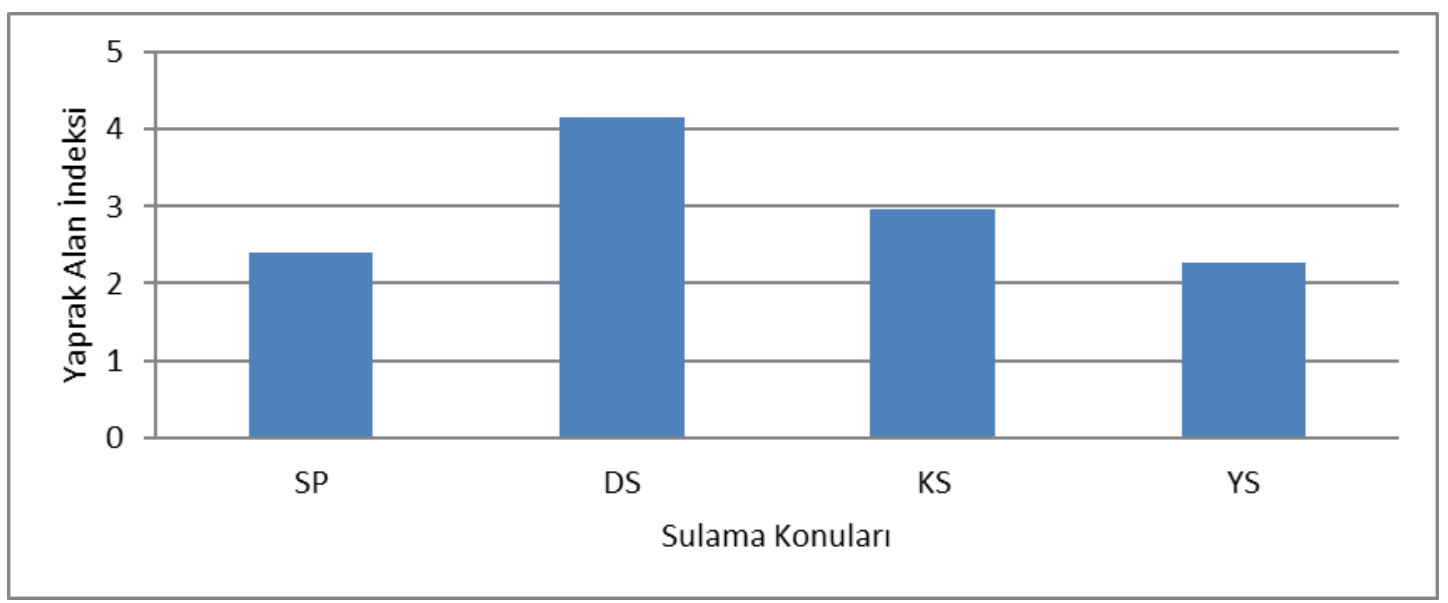

Şekil 6. Sulama konularında yaprak alan indeksleri

Figure6. The leaf area index in irrigation subjects

Farklı sulama yöntemlerine göre yaprak alan indeksi değerlerinin değiştiği görülmektedir (Şekil 6). Yaprak alan indeksi
SP konusunda 2.4, DS konusunda 4.2, KS konusunda 3.0, ve YS konusunda ise 2.3 olarak bulunmuştur.

Çizelge 6. Yaprak alan indeksi tanıtıcı özellik ve varyans analizi

Table 6. The identifier feature and variance analysis of the leaf area index

\begin{tabular}{|c|c|c|c|c|c|c|c|c|c|c|}
\hline $\begin{array}{c}\text { Değişken } \\
\text { Variable }\end{array}$ & $\begin{array}{c}\text { Grup } \\
\text { Group }\end{array}$ & $\mathrm{N}$ & $\mathrm{N}^{*}$ & $\begin{array}{c}\text { Ortalama } \\
\text { Mean }\end{array}$ & $\begin{array}{c}\text { StHata } \\
\text { SEMean }\end{array}$ & $\begin{array}{c}\text { StSapma } \\
\text { StDev }\end{array}$ & $\begin{array}{c}\text { VarKatsayısı } \\
\text { CoefVar }\end{array}$ & $\begin{array}{c}\text { Minimum } \\
\text { Minimum }\end{array}$ & $\begin{array}{c}\text { Medyan } \\
\text { Median }\end{array}$ & $\begin{array}{c}\text { Maksimum } \\
\text { Maxsimum }\end{array}$ \\
\hline $\begin{array}{c}\text { Yaprak } \\
\text { alan } \\
\text { indeksi }\end{array}$ & DS & 3 & 0 & 4.2 & 1.397 & 1.397 & 33.61 & 2.567 & 4.716 & 5.188 \\
\hline & KS & 3 & 0 & 3.0 & 0.983 & 0.983 & 33.15 & 1.853 & 3.331 & 3.715 \\
\hline & SP & 3 & 0 & 2.4 & 0.0848 & 0.0848 & 3.55 & 2.3198 & 2.3655 & 2.4842 \\
\hline & YS & 3 & 0 & 2.3 & 0.198 & 0.198 & 8.72 & 2.109 & 2.205 & 2.489 \\
\hline
\end{tabular}

Yaprak alan indeksi özelliği bakımından verilere yapılan varyans analizi sonuçlarında, sulama yöntemlerinin ortalamalar arasındaki farklar istatiksel olarak önemli değildir.

\section{Sonuçlar}

Çalışmaya konu olan sulama uygulamaları 2015 Haziran ile Eylül ayları arasında gerçekleştirilip, sulama suyu miktarları bu aylara göre hesaplanmıştır. DS'nin HaziranEylül ayları arasında toplam sulama suyu miktarları 471.05 mm, KS'nin Haziran-Eylül ayları arasında toplam sulama suyu miktarları 942.10 mm olarak, YS'nin HaziranEylül ayları arasında toplam sulama suyu miktarları $591.63 \mathrm{~mm}$ olarak hesaplanmıştır. 
Yapılan ölçüm sonuçlarına göre en az su tüketimi ile en iyi gelişim parametrelerinin DS konusunda olduğu belirlenmiştir. DS konusu KS konusuna göre \%50, YS konusuna göre ise \%21 oranında daha az sulama suyu kullanılmıştır. Ayrıca DS deneme konusunda gelişim parametrelerinden boy uzunluğu 83 $\mathrm{cm}$, dal sayısı 3 adet, gövde genişliği $19 \mathrm{~mm}$, yaprak sayısı 24 adet ve yaprak alan indeksi ise 4.2 değerleri arasında ölçülmüştür.

\section{Ekler}

Bu çalışma "Genç Antepfıstığı Ağaçlarında Farklı Sulama Yöntemlerinin Gelişim Parametrelerine Etkisi" isimli yüksek lisans tezinden türetilmiş ve SDÜ-BAP (3895-YL1-14 nolu proje) birimi tarafından desteklenmiştir.

\section{Kaynaklar}

Anonim, 2014. Food and Agriculturel Organization Web Erişim Tarihi: 28/03/2016, page:http//www.fao.org.

Bilgel, L., Dağdeviren, İ., Nacar, A. S., 1999. Gap Bölgesi Harran Ovası Koşullarında Antepfıstığının Su Tüketiminin ve Sulama Programının Belirlenmesi. Türkiye 3. Bahçe Bitkileri Kongresi. 14-17 Eylül 1999, 252257s, Ankara.

Bilgen, A. M., 1973. Antepfıstığı Gıda, Tarım ve Hayvancılık Bakanlığı Basın Yayın ve Halkla Ilişkiler Dairesi Yay., Ankara, $123 \mathrm{~s}$.

Bilgen A. M.,, 1982. Verim Çağındaki Antepfıstıklarında, Normal Bakım Tedbirleri Altında Sulamanın Miktar ve Zamanının Verim ve Kaliteye Etkisinin Araştırılması, Antepfıstığı Araştırma Enstitüsü Müdürlüğü Gaziantep, $35 \mathrm{~s}$.

Caruso, T., 2001. The Desperation of The Pistachio Trees, Dipartimento Di Arboricoltura, Botanica E Patalogia Vegetale Universita Fedricoli, Napoli Italy, Abstract Artical.

Demir, C., 2016. Genç Antepfıstığı Ağaçlarında Farklı Sulama Yöntemlerinin Gelişim Parametresine Etkisi, Yüksek Lisans Tezi, Süleyman Demirel Üniversitesi, Fen Bilimleri Enstitüsü, Yüksek Lisans Tezi, 47s, Isparta.
Güngör, Y., Erözel, A. Z., Yıldırım, O., 2004. Ankara Üniversitesi Ziraat Fakültesi Tarımsal Yapılar ve Sulama Bölümü, Sulama Kitabı, Ankara, 239s.

Goldhamer, 1995. Irrigation Management Annual Report of California Pistachio Industry, Crop Year 1994-1995, s 71-82.

Hendricks L. Ferguson L, 1995. The Pistachio Tree California Pistachio Industry, Annual Report 1994-95 p, 7-10.

Kanber, R., Yükçeken, Y., Köksal, H., Önder, S., Ünlü, M., Sezen, S. M., Özekici, B., 2000. Damla Sulama Yöntemiyle Fergitasyon Uygulamalarının Antepfıstığında Gelişme, Verim ve Periyodisiteye Etkisinin İncelenmesi Ç. Ü. Ziraat Fakültesi, Tar. Yap. ve Sul. Böl. Araştırma Sonuç Raporu, Adana, $20 \mathrm{~s}$.

Kaşka, N., 1998. The Pistachio Its Traditional Growing Areas. Advanced Course Production and Economics of Nut Crops, Adana, Turkey.

Kuru, C., 1992. Antepfıstığı Dikimden Hasada Ar Ajans, Gaziantep. 102 s.

Mendes, M., 2012. Uygulamalı Bilimler İçin İstatistik ve Araştırma Yöntemleri, Kriter Yayınevi, İstanbul, 632s.

Özbek, S., 1978. Özel Meyvecilik Ç.Ü.Z.F. Yayın No:128, Ders Kitabı 11, Adana 486s.

Tekin, H., Genç, Ç., Kuru, C., Akkök, F., 1990. Antepfıstığı Besin Kapsamlarının Belirlenmesi ve En Uygun Yaprak Örneği Alım Zamanının Tespiti. Türkiye 1. Sempozyumu. 11-12 Eylül 1990. Gaziantep, 120-138s.

Ulusaraç, A. 1993. Antepfıstığı Çeşit Kataloğu Tarım ve Köy İşleri Bakanlığı Mesleki Yayınlar, Genel Yayın No:361, Seri No:20, Ankara, 64s. 